\title{
Madrasah Principal Leadership Role in Improving Teachers' Performance
}

\author{
Sarmi Sinta Putri ${ }^{1}$ Safri Mardison ${ }^{2 凶}$ \\ Manajemen Pendidikan Islam, Universitas Islam Negeri Imam Bonjol Padang, Indonesia ${ }^{1,2}$ \\ email: sarmisintaputri7@gmail.com ${ }^{1}$, safrimardison@uinib.ac.id ${ }^{2}$
}

\begin{tabular}{ll}
\hline Article info & \multicolumn{1}{c}{ Abstract } \\
\hline & This study aims to describe the role of madrasah principal in improving teachers' \\
Article History & performance. This was a descriptive qualitative study. Observation, interview, and \\
Recieved: & documentation were used to collect the data. The source of data were the principal \\
$30 / 03 / 2021$ & and teachers of MTsN 4 Muko-muko. Data were analyzed in two stages: the first \\
Accepted: & stage was preliminary observation and the second stage was the research which \\
$27 / 04 / 2021$ & included three steps, namely data reduction, data display, and data verification. \\
Published: & Trustworthiness data were tested by conducting triangulation. The result indicated \\
$10 / 05 / 2021$ & that principal leadership in improving the quality of teachers' performance \\
& included Discipline Development Supervision Program (PPD), Supervision and \\
Corresponding Author & Evaluation (SDE) activity, and Learning Program Planning. These findings are the \\
& basic of how discipline, supervision, and learning program planning become the \\
& indicators of a guidance to improve the quality of teachers' performance.
\end{tabular}

Keywords: Leadership of Madrasah Principal, Teacher Performance

\begin{abstract}
Abstrak
Tujuan penelitian ini untuk memaparkan peranan kepemimpinan kepala madrasah terhadap peningkatan kinerja guru. Penelitian ini menggunakan pendekatan kualitatif dengan analisis secara deskriptif. Teknik pengumpulan data melalui observasi, wawancara, dan dokumentasi. Sumber data berasal dari kepala madrasah dan para pendidik di Madrasah Tsanawiyah Negeri 04 Muko-Muko. Analisis data dalam penelitian ini yaitu melalui dua tahap yaitu yang pertama tahap pra lapangan yang berupa observasi dan tahap yang kedua yaitu tahap pelaksanaan penelitian yang memuat tiga tahapan yaitu reduksi data, penyajian data, dan penarikan kesimpulan. Uji keabsahan data penelitian dengan melakukan triangulasi. Hasil penelitian menunjukkan bahwa kepemimpinan yang dilakukan oleh kepala madrasah dalam meningkatkan mutu kinerja guru yaitu Program supervisi Pembinaan Disiplin (PPD), kegiatan Supervisi dan Evaluasi (SDE), dan Perencanaan Program Pembelajaran. Temuan ini menjadi dasar bagaimana kedisiplinan, supervisi dan perencanaan program pembelajaran yang dijalankan oleh kepala sekolah merupakan indikator yang dapat dijadikan panduan dalam peningkatan mutu kinerja guru.
\end{abstract}

Kata Kunci: Kepemimpinan Kepala Madrasah, Kinerja Guru

JIES is licensed under a Creative Commons Atribution-Share Alike 4.0 Internasional Licence

(c) 90 


\section{PENDAHULUAN}

Pendidikan merupakan sarana yang dapat menjadikan tumbuhnya insan-insan dari suatu bangsa yang cerdas. Dalam membentuk sumber daya manusia yang memiliki pribadi yang berkualitas harus didukung oleh lembaga pendidikan yang memiliki mutu dan standar yang baik guna menunjang tercapainya dari tujuan pendidikan nasional Indonesia (Ningrum, 2016).

Salah satu kunci efektifnya pengelolaan pada suatu lembaga pendidikan diperankan oleh kepemimpinan dari kepala sekolah yang memiliki tanggung jawab terhadap dinamika dan perubahan perilaku kerja dari bawahannya dengan dapat menghadirkan ide-ide baru sehingga interaksi yang terjalin di lingkungan lembaga pendidikan dapat berjalan baik sesuai dengan cita-cita dari lembaga (Warmansyah, 2020). Hal tersebut senada dengan penelitian Subaidi (2020), yang menyebutkan bahwa peningkatan kinerja guru berhubungan dengan bagaimana kepemimpinan kepala sekolah dapat menunjukkan teladan kepada bawahannya serta memberikan dorongan motivasi kepada guru, dan tenaga kependidikan, untuk dapat menjalankan tugas-tugas yang sesuai dengan ketentuan yang telah ditetapkan.

Sebagai pemimpin kepala sekolah memainkan peran utama dalam memulai kegiatan dan memfasilitasi atau membantu tindak lanjut dari program-program pengembangan yang telah direncanakan. Sejauh mana kepala sekolah menangani program-program pengembangan tersebut akan menentukan keberhasilan sekolah (Niswaty, 2018). Fitrah (2017), dalam kajian penelitiannya menyimpulkan bahwa untuk memperoleh hasil yang baik dari prestasi kerja guru perlu adanya perubahan dramatis pada peran kepala sekolah yang fokus pada masalah manajerial dalam lembaga pendidikan yang dipimpinnya.

Pimpinan dalam satuan pendidikan harus mempunyai fondasi kepemimpinan yang kuat dan memiliki tanggung jawab dari maju mundur sekolah yang dipimpinnya. Kepala sekolah berperan dalam proses merancang, mempersiapkan, melaksanakan, mengarahkan, dan memimpin solidaritas dan persatuan semua program dan memasukkan seluruh sumber daya untuk mencapai tujuan yang telah targetkan (Syamsul, 2017).

Sebuah sekolah merupakan organisasi dengan tingkat kompleksitas yang cukup tinggi sehingga dibutuhkan koordinasi dan sinergi agar tercapainya target dan cita-cita warga sekolah, oleh karena itu peranan kepala sekolah dalam organisasi dan hubungan kerja dengan bawahannya sangat diperlukan (Werang, 2014). Dalam dunia pendidikan, guru adalah salah satu yang menentukan dari keberhasilan pendidikan di sekolah, karena guru memiliki kinerja yang memadai untuk menghasilkan siswa yang dapat dipercaya dan berkualitas (Ardiana, 2017).

Guru berperan aktif dalam proses pembelajaran untuk pembentukan sumber daya manusia (Saat, 2015). Pencapaian tujuan pendidikan terletak dari upaya seorang guru bagaimana dapat mengembangkan potensi siswa, menjadikan siswa berkarakter, beriman dan berakhlak mulia serta memiliki kecakapan dan keterampilan hidup (Muhammad Fadhli, 2017). Hal ini diperkuat oleh penelitian yang dilakukan oleh 
Madrasah Tsanawiyah Negeri 04 Muko-Muko merupakan salah satu lembaga pendidikan yang telah melakukan kegiatan peningkatan kinerja guru oleh kepala Madrasah. Keberhasilan kepala sekolah dalam meningkatkan mutu kinerja guru mejadi alasan penting penelitian ini dilakukan. Oleh sebab itu penelitian ini dilakukan agar dapat mengetahui tentang peranan kepemimpinan kepala sekolah dalam peningkatan kinerja guru di lembaga pendidikan yang dipimpinnya, sehingga di harapkan dapat diketahui secara jelas tentang kepemimpinan kepala sekolah dalam meningkatkan kinerja guru .

\section{METODE PENELITIAN}

Pendekatan kualitatif digunakan oleh peneliti dengan mendeskrispsikan hasil kajian yang ditemukan di lapangan melalui pengungkapan fakta-fakta dari permasalahan yang ada di lapangan dengan mengumpulkan beragam informasi yang ada baik berupa kata-kata, gambar, dan bentuk lainnya yang dapat mendukung kondisi yang sesuai dengan fakta lapangan.

Lokasi yang menjadi tempat penelitian penulis yaitu di Sekolah MTSN 04 MukoMuko yang berada di Kecamatan Malin Deman Kabupaten Muko-Muko Kota Bengkulu. Data-data primer diperoleh dari sumber primer melalui wawancara dengan kepala sekolah, wakil kurikulum dan lima orang pendidik atau guru.

Teknik pengumpulan data berupa metode wawancara (Interview), observasi partisipasi (Participan Observation) dan dokumentasi. Analisis data yang diterapkan menggunakan reduksi data, paparan atau penyajian data dan penarikan kesimpulan yang dilakukan selama dan sesudah penelitian

\section{HASIL DAN PEMBAHASAN}

Dari hasil penelitian ditemukan kepemimpinan kepala Madrasah Tsanawiyah Negeri 04 Muko-Muko terhadap peningkatan kinerja guru yaitu melalui program pembinaan disiplin (PPD), Kegiatan Supervisi dan Evaluasi (SDE), Perencanaan Program Pembelajaran (PPP). Adapun gambaran hasil temuan penelitian ini dapat dijelaskan sebagai berikut:

\section{Kepemimpinan kepala Madrasah Tsanawiyah Negeri 04 Muko-Muko Untuk Meningkatkan Kinerja Guru Melalui Program Pembinaan Disiplin (PPD)}

Pembinaan disiplin merupakan segala sesuatu secara teratur dan terarah serta suatu keadaan yang tertib di mana anggota yang berada dalam suatu organisasi tersebut dapat mengikuti aturan yang berlaku yang sesuai dengan kondisi dan melihat aturanaturan organisasi merupakan perilaku yang bisa diterima. Disiplin disebut berhasil apabila pegawai maupun tenaga kependidikan secara umum mengikuti aturan-aturan organisasi dan disebut gagal apabila aturan dari organisasi yang telah ditetapkan dilanggar. Program pembinaan disiplin ini menjadi salah satu program di Madrasah Tsanawiyah Negeri 04 Muko-Muko yang sangat berperan penting dalam meningkatkan 
kinerja guru agar guru memiliki kedisiplinan yang kuat dalam mendidik peserta didiknya, meningkatkan kinerja guru di sebuah sekolah itu amatlah penting.

Hasil wawancara dengan kepala madrasah menyebutkan bahwa "Pembinaan disiplin merupakan suatu program wajib yang ada di Madrasah sebagai seorang pimpinan. Selaku pimpinan harus memberikan teladan yang baik terhadap bawahan yang akan diikuti pula oleh para guru. Guru yang disiplin maka para siswanya juga akan disiplin oleh karena itu guru harus hadir ke sekolah sesuai dengan jadwal yang telah di jadwalkan".

Lebih lanjut beliau mengatakan dalam hal pembinaan disiplin bahwa segala aturan yang telah disusun harus di ikuti oleh semua warga sekolah dan akan dikenakan hukuman yang setimpal dengan yang telah perbuatnya, terutama jika guru tidak mengindahkan kedisiplinan dengan pemberian teguran dimulai dengan secara, namun apabila belum terjadi perubahan, maka akan sampaikan peringatan berbentuk tulisan yang isinya peringatan satu, peringatan dua dan apabila tetap melanggar yang ketiga kalinya maka akan dilakukan pembinaan.

Hal tersebut senada dengan hasil wawancara dengan tiga guru bidang studi bahasa inggris, IPA, dan seni budaya yang mengatakan bahwa "memang benar kepala sekolah menggunakan kebijakan-kebijakan terhadap guru yang lalai dengan tugas dan tanggung jawabnya akan diberi hukuman dengan cara yang komunikatif dan persuasif melalui kekeluargaan."

Hal tersebut juga di perkuat dengan hasil wawancara dengan wakil kurikulum yang menyatakan bahwa "dalam upaya untuk memperoleh hasil meningkatkan kinerja melalui program disiplin, kepala madrasah berupaya untuk menerapkan delapan indikator seperti memotivasi semangat kerja, pembinaan disiplin, pemberian penghargaan, memberi konsultasi melakukan kunjungan kelas, menujukan sikap dan perilaku teladan, membangun kelompok kerja aktif dan kreatif, mengembangkan profesi guru."

Hal tersebut sejalan dengan hasil penelitian yang dilakukan oleh Arianto (2019), yang menyebutkan bahwa lingkungan kerja dan budaya kerja memiliki hubungan dengan kedisiplinan kerja yang berdampak terhadap peningkatan kinerja guru. Hal tersebut juga ditunjang oleh hasil penelitian Rizal (2019), Kinerja guru dipenagruhi sebanya 50\% dari motivasi kerja serta kedisiplinan yang dimiliki oleh masing-masing guru di satuan pendidikan tempat berkerja.

Temuan di atas dipertajam oleh dukungan penelitian Hadromi (2017), yang menyatakan bahwa gaya kepemimpinan kepala madrasah/sekolah dapat memberikan pengaruh yang signifikan terhadap kinerja guru serta pegawainya artinya pimpinan sebagai pembuat kebijakan dan keputusan harus memiliki strategi dalam meningkatkan kinerja guru melalui pendisiplinan pegawai di lingkungan kerjanya. Ditambahkan oleh Fatihah et al., (2019) menyebutkan bahawa guru yang profesional maka akan tampak dari mutu kinerja yang ditunjukkan di lingkungan kerjanya. 


\section{Kepemimpinan kepala Madrasah Tsanawiyah Negeri 04 Muko-Muko dalam Meningkatkan Kinerja Guru Melalui Kegiatan Supervisi dan Evaluasi (SDE)}

Supervisi dan evaluasi merupakan proses penilaian dalam upaya peningkatan kualitas ataupun proses penilaian di mana hasil penelitian tersebut akan digunakan sebagai analisis situasi berikutnya. Dalam suatu organisasi di setiap jenjang pendidikan, evaluasi dapat dijalankan oleh kepala madrasah dengan bantuan guru, petugas tata usaha, komite dan tenaga kependidikan lainnya yang berkompeten. Semua unsur yang terlibat dalam evaluasi harus memiliki kesamaan pandangan dan bertanggung jawab atas terwujudnya tujuan yang diharapkan oleh sekolah. Setelah para guru maupun tenaga kependidikan melakukan pekerjaan, setiap individu harus menyampaikan laporan hasil yang diperoleh kepada kepala madrasah.

Strategi kepala madrasah dalam pengorganisasian yaitu dengan membuat suatu perencanaan, mempersiapkan persyaratan untuk meningkatkan kinerja melalui sistem supervisi dan evaluasi guru jauh-jauh hari. Hasil wawancara dengan kepala Madrasah tentang kegiatan supervisi dan evaluasi beliau menuturkan bahwa:

"Pada Madrasah terdapat pelaksanaan supervisi dan evaluasi guru minimal satu semester satu kali disupervisi. Supervisi tersebut mengarah pada kebijakan pendidikan berikutnya, berhasil atau tidak guru dalam melaksanakan program mengajar atau melaksanakan tugas mengajarnya. Setiap guru harus disupervisi sesuai dengan peraturan yang berlaku di sekolah sehingga tergambar keberhasilan guru dan perencanan guru yang belum tercapai atau sudah tercapai".

Hal tersebut juga di perkuat dengan hasil wawancara dengan wakil kurikulum yang menyatakan bahwa "Bapak kepala madrasah melakukan supervisi dan evaluasi terhadap kinerja guru terkait dengan cara/strategi guru dalam mengajar. Hal tersebut dilakukan dengan mengunjungi kelas ketika guru sedang mengajar. Bagi guru yang memiliki kendala dalam mengajar, maka guru dipanggil oleh Bapak kepala dan diberi arahan supaya menjadi lebih baik". Selanjutnya evaluasi dilaksanakan setiap awal semester. Evaluasi supervisi administrasi di awal semester, setelah akhir semester evaluasi hasil dibuktikan dengan pemberian nilai-nilai terhadap guru."

Hal tersebut senada dengan hasil wawancara dengan tiga guru bidang studi bahasa inggris, IPA, dan seni budaya yang mengatakan bahwa "Memang Bapak Kepala Madrasah menerapkan sistem supervisi dan evaluasi di Madrasah dilakukan pada awal dan akhir semester untuk melihat kesiapan dan penvcapaian dari kinerja masing-masing guru. Semua guru melengkapi semua perangkat pembelajaran baik awal maupun akhir dan perangkat pembelajaran merupakan syarta untuk mengajar dan memberikan bimbingan terhadap siswa Melalui kegiatan supervisi memberikan peluang kepada guru untuk meningkatkan kemampuan dirinya, seperti mengikuti seminar atau menambah pendidikan di jenjang yang lebih tinggi”.

Meningkatkan kinerja melalui sistem supervisi dan evaluasi merupakan suatu strategi yang dapat dipakai untuk memberikan panduan dan pegangan bagi guru agar 
dapat bertanggung jawab dalam menyelesaikan tugas yang diembannya sesuai dengan target-target yang telah direncanakan (Wahyudi et al., 2012). Hal tersebut didukung oleh banyak penelitian sebelumnya yang menemukan bahwa kepala sekolah yang melakukan kegiatan supervisi baik akademik maupun pengawas, akan memeberikan dampak terhadap peningkatan dari kinerja guru (Aprida et al., 2020; Ramadhan, 2017; Timor, 2018; Wahidah, 2015). Artinya kepemimpinan melalui supervisi memberikan dampak peningkatan budaya kerja dan beririsan dengan mutu kinerja guru.

\section{Kepemimpinan kepala Madrasah Tsanawiyah Negeri 04 Muko-Muko dalam Meningkatkan Kinerja Guru Melalui Perencanaan Program Pembelajaran (PPP)}

Perencanaan program pembelajaran merupakan kewajiban yang harus di peruhi oleh guru, dan dikenal dengan istilah perangkat pembelajaran. Temuan terhadap dokumen-dokumen dari perencanaan program pembelajaran, yang dilihat dari salah seorang guru terlihat bahwa isi dari perangkat pembelajaran meliputi program tahunan, kalender pendidikan, program semester, alokasi waktu, silabus, RPP, analisis hasil ulangan, serta program remedi. Perencanaan tersebut harus dibuat oleh guru karena dijadikan sebagai acuan guru dalam melakukan pembelajaran di kelas, sehingga pembelajaran akan lebih teratur dan tertata. Terdapat empat poin tentang bentuk perencanaan program pembelajaran (PPP) sebagai berikut: memberikan arahan dan dorongan, memberikan workshop sesama guru mata pelajaran yang sejenis melalui forum MGMP, memberikan diklat dan pelatihan, menyediakan fasilitas.

Hasil wawancara dengan bapak kepala madrasah bahwa "selaku kepala madrasah meminta kepada seluruh guru untuk memberikan Perencanaan Program Pembelajaran (PPP) yang telah di buat, sekaligus untuk diberikan pengesahan. Selanjutnya guru didorong mengikuti workshop sesama guru mata pelajaran melalui forum MGMP dalam perencanaan program pembelajaran

Hal tersebut didukung oleh wakil kurikulum menuturkan bahwa: "Kepala sekolah memberikan arahan dan dorongan agar mampu membuat perencanaan pembelajaran dengan baik. Bagi guru yang perencanaannya kurang baik, kepala sekolah juga memberikan arahan dengan memanggil guru guru-guru yang dalam pembelajaran kurang baik setelah mengumpulkan RPP. Kepala madrasah mengadakan rapat, briefing, untuk membuat perencanaan pembelajaran dengan baik"

Hasil konfirmasi dengan tiga orang guru bidang studi menyatakan hal yang sama bahwa "Bapak kepala Madrasah mengadakan workshop penulisan RPP dan sebagainya. Mata pelajaran sejenis dengan merevisi RPP tahun lalu di perbaiki, apakah masih relevan atau tidak". Jadi, workshop tersebut dapat menjadi sarana bagi guru berdiskusi, bekerja sama dan memperbaiki perencanaan pembelajaran".

Hasil penelitian ini sejalan dengan temuan penelitian Irawati (2017), yang menemukan bahwa pengontrolan RPP merupakan salah satu bentuk supervisi dalam melakukan pengawasan terhadap terjaminnya penyelenggaraan pembelajaran yang bermutu di kelas oleh guru. Hal senada juga di sampaikan oleh Wibawa 
(2019), pembinaan kepala sekolah melalui supervisi kolegial terbukti efektif diterapkan dalam meningkatkan kinerja guru melalui supervisi kolegial secara berkelanjutan.

\section{KESIMPULAN}

Kepemimpinan kepala madrasah dalam meningkatkan kinerja guru di Madrasah Tsanawiyah Negeri Muko-Muko dalam usaha untuk meningkatkan kinerja guru melalui berbagai program yang telah dijalankan melalui pembinaan disiplin (PPD) yang harus dipatuhi oleh seluruh warga sekolah. Supervisi dan evaluasi yang diterapkan kepala sekolah memberi peluang kepada guru untuk meningkatkan kemampuan dirinya, selanjutnya meningkatkan kinerja guru melalui Perencanaan Program Pembelajaran (PPP) berupa memberikan arahan dan dorongan, memberikan workshop sesama guru mata pelajaran yang sejenis melalui forum MGMP, memberikan diklat dan pelatihan, menyediakan fasilitas merupakan wujud dari upaya kepala madrasah untuk menambah pengetahuan dan wawasan sehingga dapat membawa pengaruh positif terhadap peningkatan kinerja para gurunya.

\section{DAFTAR PUSTAKA}

Aprida, Y., Fitria, H., \& Nurkhalis, N. (2020). Pengaruh Supervisi Kepala Sekolah dan Motivasi Kerja Guru Terhadap Kinerja Guru. Journal of Education Research, 1(2), 160-164. https://doi.org/10.37985/joe.v1i2.16

Ardiana, T. E. (2017). Pengaruh Motivasi Kerja Guru Terhadap Kinerja Guru Akuntansi Smk Di Kota Madiun. Jurnal Akutansi Dan Pajak, 17(02). https://doi.org/10.29040/jap.v17i02.11

Arianto, D. A. N. (2019). Pengaruh Kedisiplinan, Lingkungan Kerja Dan Budaya Kerja Terhadap Kinerja Tenaga Pengajar. Jurnal Economia, 9(2). https://doi.org/https://doi.org/10.21831/economia.v9i2.1809

Fatihah, F., Ibrahim, M. M., \& Azisah, S. (2019). Pengaruh Kompetensi Profesional dan Kedisiplinan Guru Terhadap Kinerja Guru pada Madrasah Tsanawiyah di Kecamatan Gantarang Kabupaten Bulukumba. Manajemen Pendidikan, 14(1). https://doi.org/10.23917/jmp.v14i1.8508

Fitrah, M. (2017). Peran Kepala Sekolah Dalam Meningkatkan Mutu Pendidikan. Jurnal Penjaminan Mutu, 3(1), 31. https://doi.org/10.25078/jpm.v3i1.90

Hadromi, F. Al. (2017). Analisis Pengaruh Gaya Kepemimpinan Kepala Sekolah Terhadap Motivasi, Kedisiplinan Dan Kinerja Guru di SD Islam Lumajang. Bisma, 11(1), 109. https://doi.org/10.19184/bisma.v11i1.6212

Irawati, N. (2017). Pelaksanaan Teknik Supervisi Individual Guna Meningkatkan Kinerja Guru Dalam Menyusun Silabus Dan RPP Di SD Negeri 50 Kota Banda Aceh Tahun Pelajaran ... Jurnal Dedikasi Pendidikan, 1(2), 214-222. http://jurnal.abulyatama.ac.id/index.php/dedikasi/article/view/87 
Muhammad Fadhli. (2017). Manajemen Peningkatan Mutu Pendidikan. Tadbir : Jurnal Studi Manajemen Pendidikan, 1(2), 130-145. https://doi.org/10.46244/visipena.v4i2.218

Ningrum, E. (2016). Pengembangan Sumber Daya Manusia Bidang Pendidikan. Jurnal Geografi Gea, 9(1). https://doi.org/10.17509/gea.v9i1.1681

Niswaty, R. (2018). Pengaruh Gaya Kepemimpinan Kepala Sekolah Terhadap Kinerja Guru. Ta'dib: Jurnal Pendidikan Islam, 4(2), 91-102.

Ramadhan, A. (2017). Pengaruh Pelaksanaan Supervisi Akademik Pengawas Sekolah Dan Supervisi Kepala Sekolah Terhadap Kinerja Guru SMK Negeri Di Kabupaten Majene. Journal of Educational Science and Technology (EST), 3(2), 136. https://doi.org/10.26858/est.v3i2.3579

Rizal, A. S. (2019). Pengaruh Motivasi Kerja Dan Kedisiplinan Terhadap Kinerja Guru SMP. Jurnal Ulul Albab, 23(1), 15. https://doi.org/10.31764/jua.v23i1.658

Saat, S. (2015). Faktor-Faktor Determinan Dalam Pendidikan (Studi Tentang Makna dan Kedudukannya dalam Pendidikan). Jurnal Ta'dib, 8(2), 1-17. ejournal.iainkendari.ac.id/al-tadib/article/view/407

Subaidi, S. (2020). Kepemimpinan Kepala Madrasah Dalam Upaya Meningkatkan Mutu Pendidikan Dan Kinerja Guru di MAN 1 Pati. Tadbir : Jurnal Studi Manajemen Pendidikan, 4(2), 161. https://doi.org/10.29240/jsmp.v4i2.1428

Syamsul, H. (2017). Penerapan Kepemimpinan Kepala Sekolah Dalam Meningkatkan Kinerja Guru Pada Jenjang Sekolah Menengah Pertama (SMP). Idaarah: Jurnal Manajemen Pendidikan, 1(2). https://doi.org/10.24252/idaarah.v1i2.4271

Timor, H. (2018). Mutu Sekolah; Antara Kepemimpinan Kepala Sekolah Dan Kinerja Guru. Jurnal Administrasi Pendidikan, 25(1), 21-30. https://doi.org/10.17509/jap.v25i1.11568

Wahidah, S. (2015). Pelaksanaan Supervisi Pengajaran Oleh Kepala Sekolah Dalam Meningkatkan Kinerja Guru Di Smk Negeri 1 Banda Aceh. Jurnal Administrasi Pendidikan : Program Pascasarjana Unsyiah, 3(3), 50-57.

Wahyudi, A., Thomas, P., \& Setiyani, R. (2012). Pengaruh Disiplin Kerja, Motivasi Kerja, Dan Supervisi Kepala Sekolah Terhadap Kinerja Guru. Economic Education Analysis Journal, 1(2).

Warmansyah, J. (2020). Supervisi Akademik Kepala Sekolah Taman Kanak-kanak Dimasa Pandemi Covid 19. Tadbir : Jurnal Studi Manajemen Pendidikan, 4(2), 175. https://doi.org/10.29240/jsmp.v4i2.1695

Werang, B. R. (2014). Pengaruh Kepemimpinan Transformasional Kepala Sekolah, Moral Kerja Guru, Dan Kepuasan Kerja Terhadap Kinerja Guru SDN di Kota Merauke. Jurnal Cakrawala Pendidikan, 1(1). https://doi.org/10.21831/cp.v1i1.1869 
Wibawa, I. M. D. (2019). Meningkatkan Kinerja Guru dalam Menyusun Silabus dan Rencana Pelaksanaan Pembelajaran (RPP) melalui Supervisi Kolegial. Journal of Education Action Research, 3(1), 66. https://doi.org/10.23887/jear.v3i1.17092 